identical. Details of doctors' grade and specialty and the date of any previous instruction on defibrillation technique were also recorded.

Data were collected from 20 consultants, 2 staff grades, 38 registrars, 31 senior house officers, and 10 preregistration house officers. There was no significant difference (determined by analysis of variance) in paddle positioning between different grades or specialties or between those who had received defibrillation instruction within the past three years and those who had not.

Results are shown in the figure. The positions for the sternal and apical paddles specified by the European Resuscitation Council are shown. Sixty five per cent of sternal paddles were placed within $5 \mathrm{~cm}$ (approximate radius of a defibrillation paddle) of the position recommended in the guidelines. ${ }^{2}$ Most apical paddles were placed too medially and too cranially, only $22 \%$ being placed within $5 \mathrm{~cm}$ of the position recommended by the guidelines. $^{2}$

\section{Comment}

Adherence to European Resuscitation Council guidelines for defibrillation paddle position is poor, resulting in incorrect paddle placement, particularly of the apical paddle, by most doctors, irrespective of grade, specialty, or how recently they had been instructed on technique. Apical paddle placement is usually too medial, reducing the separation of the paddles.

Since this study was performed, the International Liaison Committee on Resuscitation (ILCOR) has published guidelines which supersede those of the European Resuscitation Council and which specify even more lateral placement of the apical defibrillation paddle, "to the left of the nipple with the center of the electrode in the mid-axillary line." ${ }^{.4}$ This is the position previously advocated by the American Heart Association. $^{5}$

Incorrect paddle placement will result in a greater percentage of current passing through non-cardiac tissue and will reduce the chances of successful defibrillation through failure to depolarise a critical mass of myocardium. Teaching of advanced life support must place greater emphasis on paddle position if success of defibrillation is to be optimised.

Contributors: CD had the original idea and assisted RH and DS in designing the study, analysing the results, and drafting the paper. RH and DS collected and interpreted the data. CD is guarantor for the paper.

Funding: None.

Competing interests: None declared.

1 Part 4: the automated external defibrillator: key link in the chain of survival. Resuscitation 2000:46:73-91.

2 Robertson C, Steen P, Adgey J, Bossaert L, Carli P, Chamberlain D, et al. The 1998 European Resuscitation Council guidelines for adult advanced life support: a statement from the Working Group on Advanced Life Support, and approved by the executive committee. Resuscitation Support, and

3 Larose D. Teaching optimal paddle position for defibrillation [letter]. Ann Emerg Med 1993;22:1925.

4 Part 6: advanced cardiovascular life support. Section 2: defibrillation. Resuscitation 2000:46:109-13

5 Emergency Cardiac Care Committee and Subcommittees, American Heart Association. Guidelines for cardiopulmonary resuscitation and emergency cardiac care. Part III. Adult advanced cardiac life support. JAMA 1992;268:2199-241.

(Accepted 17 January 2001)

\title{
Differences in therapeutic consequences of exercise testing between a rural and an urban Danish county: population based study
}

\author{
Troels Niemann, Torsten Toftegaard Nielsen, Niels Thorsgaard, Jørgen Lous
}

Medical Research Unit of Ringkøbing County, 6950 Ringkøbing, Denmark

Troels Niemann research fellow

continued over

BMJ 2001;322:1394-5

\section{bmj.com}

This article is part of the BMJ's randomised controlled trial of open peer review. Documentation relating to the editorial decision making process is available on the BMJ's website
Coronary angiography is the main diagnostic test for deciding whether to refer a patient for coronary revascularisation, but referral for coronary angiography may vary significantly among regions. ${ }^{12}$ Regional differences have been explained by the fact that access to cardiac catheterisation facilities is associated with a higher likelihood of undergoing angiography. ${ }^{3}$ We investigated the impact of exercise stress testing on decisions taken about patients suspected of having angina pectoris and the barriers to referral for coronary angiography.

\section{Subjects, methods, and results}

We identified all exercise tests and coronary angiography performed during 1996 in two Danish counties, Aarhus (urban) and Ringkøbing (rural), with five hospitals in each county. The total study population was about 900000 inhabitants. Invasive cardiac facilities were available only in Aarhus but were for use of both counties. Data from the County
Public Health Authorities on the number of admissions resulting from acute myocardial infarction and from the Danish National Board of Health on mortality from suspected ischaemic heart disease showed a similar or slightly higher prevalence of ischaemic heart disease in Ringkøbing in 1996.

A total of 2934 patients underwent bicycle exercise testing and 1691 patients underwent coronary angiography. Age adjusted rates of exercise testing were 3315 (urban) and 3183 (rural) per million inhabitants (rate ratio 1.04 (95\% confidence interval 0.96 to 1.11$)$ ). Age adjusted angiography rates were 2162 (urban) and 1244 (rural) per one million inhabitants (1.74 (1.66 to 1.83)). Proportions of patients with an exercise test result that suggested disease (angina pectoris, severe ischaemia on electrocardiography, or decreased blood pressure) were similar among the 10 hospital catchment areas (table). The decision to refer for coronary angiography a patient who had a test result that suggested disease was taken either by a 
Exercise testing and angiography in 10 hospital catchment areas in two Danish counties, one rural and one urban

\begin{tabular}{|c|c|c|c|c|c|}
\hline $\begin{array}{l}\text { Hospital catchment } \\
\text { area }\end{array}$ & $\begin{array}{l}\text { No of exercise tests per } \\
\text { million inhabitants }\end{array}$ & $\begin{array}{l}\text { Angiography per million } \\
\text { inhabitants }\end{array}$ & $\begin{array}{l}\text { Percentage of exercise } \\
\text { tests suggesting } \\
\text { disease }\end{array}$ & $\begin{array}{c}\text { Percentage of exercise } \\
\text { tests suggesting disease } \\
\text { that led to referral for } \\
\text { angiography }\end{array}$ & $\begin{array}{c}\text { Distance }(\mathrm{km}) \text { from } \\
\text { hospital to angiography } \\
\text { centre }\end{array}$ \\
\hline \multicolumn{6}{|l|}{ Rural (Ringkøbing): } \\
\hline 1 & 2213 & 940 & 28 & 33 & 154 \\
\hline 2 & 2978 & 1645 & 31 & 33 & 128 \\
\hline 3 & 4044 & 1451 & 27 & 41 & 127 \\
\hline 4 & 3649 & 1090 & 30 & 40 & 116 \\
\hline 5 & 2931 & 1326 & 28 & 58 & 82 \\
\hline \multicolumn{6}{|l|}{ Urban (Aarhus): } \\
\hline 1 & 3965 & 2441 & 28 & 69 & 62 \\
\hline 2 & 2000 & 1576 & 27 & 53 & 42 \\
\hline 3 & 3835 & 2292 & 25 & 61 & 36 \\
\hline 4 & 4278 & 1519 & 23 & 79 & 21 \\
\hline $5^{*}$ & 3634 & 2683 & 26 & 63 & 2 \\
\hline
\end{tabular}

${ }^{\star}$ Two different units with bicycle exercise testing in Aarhus University Hospital, but serving the same hospital area population.

medical consultant at the local hospital or by a cardiology specialist (three in each county). Stratified for age, the relative risk of referral (urban versus rural) for angiography (if an exercise test result suggested disease) was 2.06 (1.39 to 3.05) for women and 1.27 (1.09 to 1.50) for men. Adjustment for history of myocardial infarction did not affect the relative risk. The highest proportion of patients (per million inhabitants) with a test result that suggested disease who were referred for angiography was 79\%-in the hospital catchment area $21 \mathrm{~km}$ from the angiography centre. The lowest proportion was 33\%-in two areas $128 \mathrm{~km}$ and $154 \mathrm{~km}$ away. A linear regression was significant $(\mathrm{P}<0.01)$ with a slope of -0.78 .

\section{Comments}

Referral for coronary angiography in patients with a bicycle exercise test suggesting disease varied strongly with the distance from the angiography centre, showing that triage by medical consultants may constitute a barrier to referral for coronary angiography.

The two Danish counties in this study did not differ in their rates of exercise testing, and the doctors gave similar interpretations of the test results. No economic restrictions affected referral of patients from any of the local hospitals to the angiography centre, and both counties had similar policies on the management of healthcare problems.

The clear association between the distance to the coronary angiography service and the doctor's decision to refer the patient for coronary angiography presumably reflects different local medical cultures rather than problems with the transport of patients. Our data show that the medical specialist is a major barrier to referral for coronary angiography. The observed differences in practice between centres have implications for the organisation of the coronary angiography service, the diffusion of new technology, the use of guidelines, and continuing performance development. It is not known whether the observed differences in 1996 reflect appropriate or inappropriate use of medical resources; this issue deserves further investigation.

We thank Professor Henrik Toft Sørensen for epidemiological support.

Contributors: TN and NT had the original idea, and TTN and JL helped to design the study. TN collected and analysed data and drafted the paper. TTN, NT, and JL helped to interpret the data and revise the paper. TN is guarantor for the study. Funding: A research grant from Ringkøbing County. Competing interests: None declared.

1 Niemann T, Lous J, Thorsgaard N, Nielsen TT. Regional variations in the use of diagnostic coronary angiography. A one-year population-based study of all diagnostic coronary angiographies performed in a rural and an urban Danish county. Scand Cardiovasc J 2000;34:286-92.

2 Gray D, Hampton JR. Variations in the use of coronary angiography in three cities in the Trent Region. Br Heart J 1994;71:474-8.

3 Every NR, Larson EB, Litwin PE, Maynard C, Fihn SD, Eisenberg MS, et al. The association between on-site cardiac catherization facilities and the use of coronary angiography after acute myocardial infarction. $N$ Engl $J$ Med 1993;329:546-51.

4 Pilote L, Califf RM, Sapp S, Miller DP, Mark DB, Weaver WD, et al. Regional variation across the United States in the management of acute myocardial infarction. GUSTO-1 Investigators. Global utilization of streptokinase and tissue plasminogen activator for occluded coronary arteries. N Engl J Med 1995;333:565-72.

(Accepted 17 January 2001)

\section{Corrections and clarifications}

Adverse events in British hospitals: preliminary retrospective record review

Two errors persisted to publication in this article by Charles Vincent and colleagues (3 March, pp 517-8). The first column heading in table 2 should read "No of adverse events" [not "No of patients with adverse events"], and the penultimate section should read: "Overall, 57 [not 53] (48\%) adverse events were judged preventable." It should also have been made clear that some of the authors' results had already been published earlier in the BMJ (1999;319:1091); in Organisation With a Memory (a report by an expert group, chaired by Donaldson, on learning from adverse events in the NHS); and in Clinical Governance Bulletin.

Minerva

The caption to the photograph submitted by I Grant and colleagues (28 April, p 1072) correctly referred to the left side of the man's face being affected, but unfortunately we published the photograph the wrong way round.

Two more medical schools to open In the final paragraph of the website version of this news article by Lynn Eaton (7 April, p 816) Newcastle University was inadvertently omitted from the list of new medical schools and places. Newcastle University has been in collaboration with Durham University-the venture has therefore been a joint one. sentence in the second paragraph of the results the chief medical officer for England, Liam
Cardiology Department, Aarhus University Hospital, Skejby, 8200 Aarhus N, Denmark

Torsten Toftegaard

Nielsen

professor in cardiology

Medical

Department,

Herning Central

Hospital, 7400

Herning, Denmark

Niels Thorsgaard

specialist in internal

medicine

Institute of General

Practice and

Research Unit for

General Practice,

Aarhus University,

8000 Aarhus C,

Denmark

Jørgen Lous

assistant professor in

general medicine

Correspondence

and requests for

reprints to:

T Niemann,

Finsensgade 26,

7400 Herning,

Denmark

t.niemann@

dadlnet.dk 